\title{
Apuntes sobre la licitud de la copia
}

\author{
$* * * *$ \\ Natalia Celena Tobón \\ Profesional independiente \\ nataliatobon@hotmail.com
}

Recibido: 2 de noviembre de 2021

Aceptado: 28 de noviembre de 2021

\section{Resumen}

Los autores defienden la licitud de la copia de una obra -literaria, artística, arquitectónica, fotográfica, de bellas artes- cuando la obra que se duplica no es original; cuando la obra que se reproduce está en el dominio público -y se honra el derecho de paternidad-; y cuando la copia se hace sin incurrir en competencia desleal o enriquecimiento ilícito.

Palabras clave: copia, plagio, derecho de autor, competencia desleal, enriquecimiento ilícito.

\section{Notes on the Legality of Plagiarism}

\begin{abstract}
The authors defend the legality of the copy of a work - literary, artistic, architectural, photographic, of fine arts - when the work that is duplicated is not original, when the work that is reproduced is in the public domain and the right is respected of paternity, and when the copy is made without incurring in unfair competition or illicit enrichment.
\end{abstract}

Key words: copy, plagiarism, copyright, unfair competition, illicit enrichment.

\section{Notas sobre a legalidade do plágio}

\section{Resumo}

Os autores defendem a legalidade da cópia de uma obra - literária, artística, arquitetônica, fotográfica, de artes plásticas - quando a obra duplicada náo é origi- 
nal, quando a obra reproduzida é do domínio público e o direito é respeitado de paternidade, e quando a cópia for feita sem incorrer em concorrência desleal ou enriquecimento ilícito.

Palavras-chave: cópia, plágio, direitos autorais, concorrência desleal, enriquecimento ilícito.

Nada es original, todo es un remix.

Marco Velasco ${ }^{1}$

\section{Introducción}

Dicen que Picasso sostenía que "los grandes artistas copian, los genios roban”, pero a los abogados especialistas en propiedad intelectual se nos dilata la pupila cuando leemos esto. Olvidamos que casi nada es original y que todo, incluso esto que está leyendo, es fruto de una cabeza en la cual han intervenido una multitud de factores -educación, lecturas, formación jurídica y hasta gustos artísticosque influyen en el resultado, en el ánimo y en la creatividad.

$Y$ es que si lo pensamos bien, casi ninguna creación es original. La mayoría son el resultado de la imitación -consciente o inconsciente- de algo anterior y ello, salvo que se haga violando la ley, como veremos más adelante, es lícito e incluso benéfico. Nada más recordemos que Albert Einstein advertía que "el juego combinatorio parece ser la característica esencial en el pensamiento productivo" y Mark Twain comentaba que "sustancialmente todas las ideas son de segunda mano, consciente e inconscientemente extraídas de un millón de fuentes externas".

Es más, no todas las copias están en la misma categoría. Ya lo decía T. S. Elliot, un poeta famoso: "Los poetas inmaduros imitan; los poetas maduros roban; los malos estropean lo que roban, y los buenos lo convierten en algo mejor" (como se citó en Molina, 2016, párr. 1).

En este artículo no se trata de hacer una apología de la copia, sino

1 Blog de Marco Velasco. https://macoaconico.medium.com/nada-es-original-todo-es-un-remix-tercera-parte-7629abc95071. El autor agrega: "Y dijo Dios: 'Hagamos al hombre a nuestra imagen, conforme a nuestra semejanza' Génesis 1:26”. 
de reconocer que legalmente es posible construir sobre lo construido teniendo ciertas precauciones relacionadas con temas como la originalidad, la competencia desleal y el enriquecimiento sin causa.

\section{Algo de historia}

Desde el año 700 a. C. existen pruebas del interés de la humanidad por la protección de la autoría de las obras del intelecto humano. En efecto, hay evidencias de que en la colonia griega de Síbari -región de Calabria, Italia- los cocineros tenían derecho a patentar temporalmente los platos de comida que inventaban (Ateneo. Deipnosofist., 349). Esta protección se aplicaba a la técnica real de preparar un plato y al texto de una receta (Fabiani, 1987).

Sin embargo, para las civilizaciones de la antigüedad el concepto de "autoría" era totalmente diferente al que existe actualmente. Por ejemplo, en las culturas aborígenes de Âfrica las técnicas artísticas apenas se heredaban mediante el parentesco o a través de la tradición de sus clanes (Brain, 1980).

Para los autores de la antigua Grecia, particularmente en ciudades como Atenas, Esparta y Siracusa, las ideas se presumían regalos de los dioses; los griegos siempre invocaban a las musas como su principal fuente de inspiración y, en consecuencia, no podían ser objeto de venta o apropiación individual (Bappert et al., 1962).

Platón criticaba, con toda razón, la inspiración divina de los griegos. De los poetas, por ejemplo, el filósofo decía que solo podían escribir poemas gracias a los dioses y por eso no eran capaces de interpretar sus propias obras (Ion. 533c-536d). Sócrates, por el contrario, era de los que pensaba que las ideas y el conocimiento no se podían apropiar ni vender porque tenían un valor superior al dinero.

Pese a lo anterior, los griegos entendían que se debía respetar el trabajo intelectual. Algunos autores narran que cuando Hermodoro de Siracusa anotó las lecciones de Platón para luego venderlas en Sicilia, dio lugar a tal desprecio en Grecia que la frase "con los diálogos de Platón, Hermodoro hace negocios” se volvió típica en la región (Zenobio. v. 6; Cic. ad. Att. xiii. 21, 4).

El pueblo judío fue uno de los pocos de la antigüedad en tener una legislación expresamente referida a un derecho de autor. La ley 
judía prohibía la reclamación falsa de autoría sobre libros y manuscritos, al tiempo que desalentaba el robo de las ideas. Cuando los pescadores judíos utilizaban peces muertos en sus redes como carnada para pescar, la selección, disposición y forma de colocar el cebo eran propias de cada pescador, lo que implicaba un valor intelectual que se protegía bajo ley judía. La regla era que las redes debían mantenerse alejadas unas de otras, para así evitar que los pescadores más flojos se aprovechasen del ingenio y la técnica de los más hábiles (Kahaner, 2003, p. 179).

$\mathrm{Al}$ comienzo del primer milenio d. C. florecía en Roma un importante comercio de libros y de otras obras artísticas, pero no existían leyes que les reconocieran a escritores y artistas un derecho de dominio sobre las obras intelectuales (Rengifo, 2003). Solo las fuentes no jurídicas que se tienen de la época parecen demostrar que entonces se procuraba respetar la paternidad sobre las obras artísticas y literarias.

Durante los siguientes 400 años, Europa entendió lentamente el concepto de "obra intelectual". La expresión de las ideas empezó a reconocerse y escritores, escultores, pintores y músicos recibieron el privilegio de ser llamados "autores" ante la sociedad (Woodmansee, 1984, p. 429).

Gutenberg inventó la imprenta en Europa a mediados del siglo XV. A partir de ese instante, los Gobiernos de Italia, Francia e Inglaterra comenzaron a otorgar privilegios exclusivos para la explotación económica de las obras literarias.

Toda esta historia se cita para introducir la idea de que la copia siempre ha existido. ¿Será cierto que la inspiración viene de los dioses? ¿Será suficiente sancionar al copista con el escarnio público sin necesidad de tipificar tal acción como un delito? ¿Debe sancionarse todo plagio o solo el de obras que puedan calificarse como originales? En este estudio exponen algunas de las respuestas a estas preguntas.

\section{El derecho de propiedad intelectual no es absoluto}

El derecho de propiedad intelectual que nos rige actualmente otorga una protección relativa, no absoluta, por lo menos en Colombia. En efecto, en este país el derecho de propiedad en general es objeto de limitaciones tal y como lo dispuso la Corte Constitucional, al ana- 
lizar el texto del artículo 669 del Código Civil de 1886, cuyo texto original disponía:

El dominio (que se llama también propiedad) es el derecho real en una cosa corporal, para gozar y disponer de ella arbitrariamente, no siendo contra ley o contra derecho ajeno. ${ }^{2}$

Cabe aclarar que la palabra arbitrariamente fue declarada inexequible -contraria a la Constitución-, "pues todo derecho tiene que armonizarse con los demás que con él coexisten". ${ }^{3}$

Con anterioridad a este pronunciamiento, la Corte Suprema de Justicia ya se había referido a la función social y a los límites del derecho de propiedad:

\begin{abstract}
El sentido netamente individual de la propiedad, heredado del derecho romano, que la concibió como concentración de poderes o atribuciones del dueńo sobre sus bienes en cuya virtud éstos quedan sometidos directa y totalmente a su señorío con el fin de satisfacer únicamente sus egoístas intereses, ha venido cediendo el paso a una concepción marcadamente solidarista o funcionalista que, sin desconocerle al titular la facultad de utilizar, usufructuar y disponer libremente de los bienes en su provecho, le impone el deber de enrumbar el ejercicio de ese derecho por los cauces del bien común para que las ventajas que de él fluyan, se extiendan a la comunidad, en cuya representación actúa el propietario en función social. ${ }^{4}$
\end{abstract}

Estas limitaciones también se extienden a la propiedad intelectual, pues la Corte Constitucional sentenció expresamente que esta, como cualquier derecho de propiedad, está sujeta "a las restricciones y obligaciones que implican la función social, aplicable a todas las formas y expresiones del dominio (art. 58 ejusdem), y la prevalencia del interés general (Constitución Política, art. 10)".5

\footnotetext{
2 Cursiva agregada.

3 Corte Constitucional de Colombia, Sentencia C-595, agosto 18/99.

4 Corte Suprema de Justicia de Colombia, Sentencia, agosto 11/88.

5 Corte Constitucional de Colombia, Sentencia T-381, septiembre 14/93.
} 
La temporalidad de la protección contemplada en el artículo 61 de la Constitución, norma según la cual "el Estado protegerá la propiedad intelectual por el tiempo y mediante las formalidades que establezca la ley”, es tal vez la demostración más clara de una limitación, pues con posterioridad al vencimiento de una patente o un derecho patrimonial de autor - por ejemplo, la invención y la obrapasan a enriquecer el dominio público, en el que cualquier persona puede usarlas sin pagar contraprestación. Existen otras situaciones que permiten pensar que existen más limitaciones a la propiedad intelectual en nuestro país, aunque en otras latitudes la situación es similar. Tenemos la exigencia de conceder licencias obligatorias sobre patentes si no se han explotado al cabo de un tiempo (Decisión 486 de 2000, artículo 61), la posibilidad de solicitar la cancelación de marcas que no hayan sido usadas en los tres años anteriores a la fecha de solicitud de cancelación (Decisión 486 de 2000, artículo 165) y las limitaciones al derecho de autor conocidas como "uso justo" o fair use (como el derecho de cita y el derecho de reproducción de partes de una obra para la ilustración y enseñanza, por ejemplo).

\section{La importancia del dominio público}

Generalmente se aducen tres principios para justificar la existencia de las distintas figuras de la propiedad intelectual: el principio de la recompensa, el de la recuperación y el del conocimiento público difundido o de beneficio general.

El primero sostiene que se debe incentivar económicamente a un inventor o artista por el tiempo y esfuerzo que invierte en el trabajo que realiza. Aunque se trata de una explicación lógica, algunos estudios demuestran que la mayoría de los inventores y artistas no crean pensando en una recompensa económica, sino que actúan por curiosidad, por el deseo de resolver un problema y por la pasión por algo que les gusta (Savitsky, 2004).

El segundo, el principio de la recuperación, busca que el inventor o el artista recupere lo que invirtió en el desarrollo del invento o la creación artística y se sienta motivado para iniciar nuevas indagaciones. Sin embargo, en este punto se presentan varios interrogan- 
tes: ¿cómo valorar las inversiones en investigación y desarrollo?, ¿se debe recuperar la inversión en promoción y publicidad?, ¿y si las invenciones las hacen universidades o entidades públicas con fondos públicos?

El tercer principio, el del conocimiento público difundido, es tal vez el más importante de los tres porque le hace contrapeso a los dos anteriores. Con él se persigue que después de recompensar al creador de una obra protegida por la PI durante un tiempo, otorgándole la facultad de excluir a otros de la explotación de su creación, esta pase al dominio público para que la sociedad en general se beneficie. Este principio se origina en el siguiente razonamiento: nada nace por generación espontánea. Todas las creaciones del espíritu son fruto del esfuerzo de un ser humano que obtiene la inspiración en el marco de una sociedad específica que le proporciona la materia prima:

\begin{abstract}
Tanto a nivel tecnológico como artístico, un nuevo aporte nunca es un fenómeno individual. De allí que el derecho de propiedad sobre dichos aportes no sea intemporal sino que, por un fenómeno convencional de transacción entre el mínimo que exige el goce exclusivo y el máximo de difusión que la comunidad exige, se fija discrecionalmente por el legislador un término razonable al cabo del cual el derecho individual de propiedad se extingue. La temporalidad del derecho intelectual busca finalmente resolver la tensión que existe entre el interés privado y el interés público. ${ }^{6}$
\end{abstract}

Una obra que está en el dominio público puede ser reproducida libremente.

El dominio público en materia de derechos de autor implica que nadie tiene un derecho de exclusiva para gozar de las facultades patrimoniales sobre la obra, y, en consecuencia, la obra puede ser explotada por cualquier persona, por lo cual no hay en sentido estricto, un dominio como no lo hay sobre el aire o la luz solar. (Pachón, 1988, p. 75)

En Colombia están en el dominio público las obras cuyo período

6 Corte Constitucional de Colomnbia, Sentencia C-334, agosto 12/93. 
de protección esté agotado; las obras folclóricas y tradicionales de autores desconocidos; las obras cuyos autores hayan renunciado a sus derechos: ${ }^{7}$ las ideas que no han sido expresadas en un medio que permita su divulgación o reproducción, es decir, las ideas que no se han convertido en una obra; las obras que carecen de originalidad; los procedimientos, los métodos de operación y los conceptos matemáticos; las noticias del día o los sucesos que tengan el carácter de simples informaciones de prensa, ${ }^{8}$ en contraposición a lo que sería una crónica, un artículo de periodismo investigativo e incluso un artículo de periodismo de opinión. Las simples informaciones de prensa o los sucesos y acontecimientos noticiosos en sí mismos no le pertenecen a nadie, ni siquiera a quien obtuvo la información. ${ }^{9}$

También los juegos están en el dominio público.

Un juego es una actividad que no constituye una obra jurídicamente hablando, ya que el juego entendido como tal, es una idea no materializada, y por lo tanto no es objeto de protección por vía del derecho de autor. Es simplemente una actividad más no una obra. ${ }^{10}$

Un rompecabezas, por ejemplo, no está protegido por el derecho de autor. La Dirección Nacional de Derechos de Autor de Colombia explicó que

no todos los trabajos o creaciones (obras) de la inteligencia pueden ser objeto de protección por el derecho de autor, así sean creativos y originales, toda vez que unos cuantos rasgos, unas palabras, aun

7 El artículo 188 de la Ley 23 colombiana señala que la renuncia por los autores o herederos a los derechos patrimoniales de la obra deberá presentarse por escrito y publicarse y será válida siempre y cuando no sea contraria a las obligaciones contraídas anteriormente.

8 Convenio de Berna, artículo $2^{\circ}$, número $8^{\circ}$.

9 Sin embargo, algunas legislaciones expresamente establecen que cuando se reproduzcan las noticias del día y las simples informaciones de prensa en su versión original será necesario expresar la fuente. $\mathrm{Al}$ respecto, véase el artículo 28 de la Ley 1123 de 1933 de Argentina.

10 Dirección Nacional de Derecho de Autor. Concepto 2-2005-329 del 14 de enero de 2005. 
cuando provoquen placer estético no son obras y por ende no son protegibles por la disciplina autoral. ${ }^{11}$

No obstante lo anterior, los escritos que describen los juegos sí podrían estar protegidos por el derecho de autor, siempre que cumplan con todos los requisitos correspondientes. Sin embargo, la protección de tales documentos solo servirá para impedir la reproducción, comunicación pública, difusión y transformación de tal escrito, pero no impide que alguien lleve a cabo el procedimiento, cumpla o incumpla las reglas y lleve a cabo el juego.

En resumen, las ideas, los métodos, los sistemas, las noticias presentadas como simple información de prensa, los conceptos matemáticos y la teoría que permite desarrollar un juego no se consideran obras y, por ende, su uso es libre. No se puede adquirir sobre ellos propiedad alguna, aun cuando sean novedosos. De permitirse exclusividad, se estaría obstaculizando la difusión y el desenvolvimiento de toda la creatividad humana.

El juez norteamericano Alex Kosinki explica estas exclusiones a la protección del derecho de autor en los siguientes términos:

\begin{abstract}
¿Dónde estaríamos si Charles Lindbergh tuviera el derecho exclusivo sobre el concepto de aviador independiente? ¿Si Albert Einstein hubiera patentado la teoría de la relatividad? ¿Si cada autor o celebridad tuviera el derecho de evitar que los demás comenten su trabajo o se burlen de él? Seguramente esto haría el mundo más pobre y no más rico, cultural y económicamente. He ahí el por qué es necesario hacer balances cada que se aplican las normas de propiedad intelectual entre lo que se le otorga a su titular y lo que se le deja al dominio público, es decir, a todos nosotros. ${ }^{12}$
\end{abstract}

Ahora bien, una obra en el dominio público se puede copiar sin

11 Ibíd.

12 White v. Samsung Electronics América, Inc., U.S. 951, 113 S. Ct. 2443, 124 L. Ed. 2 Ed. 660 (1993). Salvamento de voto del juez Alex Kozinski. En el caso objeto del pronunciamiento en mención se trataba de resolver si un personaje público (Vanna White) podía demandar a una empresa por usar en su 
pagar contraprestación, pero es necesario respetar la autoría porque el derecho de paternidad sobre una obra es un derecho inalienable, inembargable e imprescriptible. ${ }^{13}$

\section{Escasez de originalidad}

¿Cómo encontrar la originalidad? ¿Por qué es importante que una obra sea original para que la ampare el derecho de autor? La Decisión 351 de 1993 aplicable en los países de la Comunidad Andina (Colombia, Ecuador, Perú y Bolivia) define a la obra protegible por el derecho de autor de la siguiente manera: "Toda creación intelectual original de naturaleza artística, científica o literaria, susceptible de ser divulgada o reproducida en cualquier forma". ${ }^{14}$

Como se observa, la originalidad es un requisito sine qua non para la protección autoral. ${ }^{15}$ Se trata de una exigencia tan importante que hay quienes sostienen que "derecho de autor" es sinónimo de "originalidad". El problema es que el término "originalidad" no ha sido definido por ninguna legislación -y es conveniente que así sea, pues

publicidad un robot que la imitaba. White ganó el proceso contra Samsung, pero Kozinski salvó el voto.

13 "De la autoría se desprenden dos tipos de derechos: los morales y los patrimoniales. Los derechos morales facultan al autor para reivindicar en todo tiempo la paternidad de la obra, oponerse a toda deformación que demerite su creación, publicarla o conservarla inédita, modificarla y a retirarla de circulación. Los derechos morales se caracterizan por ser intransferibles, irrenunciables e imprescriptibles" (Colombia, Dirección Nacional de Derecho de Autor. Concepto: 1-2013-31778, Plagio.doc).

14 Decisión Andina 351, artículo 3․ Cursiva agregada.

15 "El sine qua non del derecho de autor es que exista originalidad" (Mannion $v$. Coors Brewing Co., 2005 U.S. Dist. Memorandum Opinion. Lewis A. Kaplan. District Judge, citando Feist Publications, Inc. v. Rural Tel. Serv. Co., 499 U.S. 340, 345 (1991)). Feist es un caso clásico de derechos de autor en el que el propietario de unos directorios telefónicos demandó a otro por plagio. La Corte sentenció que, al menos en lo que respecta al derecho de autor, no había plagio pues lo que este derecho protege es la originalidad, y organizar los nombres, direcciones y teléfonos de distintas personas en orden alfabético en un directorio telefónico, si bien es una tarea que exige mucho trabajo - "sudor de la frente", mencionó la Corte-, ello no necesariamente conduce a que el resultado sea original (como se citó Tobón Franco y Varela Pezzano, 2010, p. 263). 
cualquier definición sería incompleta-, por lo que hay que acudir a la doctrina y a la jurisprudencia para desentrañar su significado.

Para algunos autores, la originalidad es una característica que puede apreciarse tanto en términos objetivos (novedad) como en términos subjetivos (reflejo de la personalidad del autor). "Basta con que la obra sea original desde uno de esos puntos de vista para que se proteja, y ello con independencia de su calidad o mérito artístico" (Bercovitz Rodríguez-Cano, 2015, s.p.).

En Estados Unidos, la jurisprudencia ha dispuesto algunos parámetros para determinar si una obra es o no original: ${ }^{16}$

o Un trabajo es original cuando no es copiado de otro.

- Una obra es original cuando tiene una chispa de creatividad.

- La originalidad no tiene que ver con la belleza ni con la estética.

- La originalidad no depende de la cantidad de trabajo -sudor de la frente- $-{ }^{17}$ ni del tiempo invertido.

El Tribunal Andino de Justicia, por su parte, ha hecho énfasis en la individualidad como requisito de la originalidad. Para este, una obra original es aquella que se puede "[d]iferenciar claramente de obras de terceros [...]. Aunque haya dos obras parecidas, se podrían considerar las originales si: 1) una no es una reproducción de la otra, y 2) tienen elementos que logran diferenciarlas o individualizarlas claramente". ${ }^{18}$

Esa individualidad mencionada por este tribunal parece aludir

16 Estados Unidos, Atari Games Corp. v. Oman, 888 F.2d 878 (D.C. Cir. 1989).

17 En Miller v. Universal City Studios, Inc., un periodista dedicó 2500 horas de investigación para escribir un libro sobre un secuestro. Universal Studios, por su parte, produjo la película en la que recreó la historia, pero no le pagó las regalías al periodista. El autor del libro demandó al estudio cinematográfico, pero la Corte favoreció a Universal Studios, pues consideró que lo que estaba protegido por los derechos de autor era la obra escrita de Miller y no los hechos ni la investigación, mucho menos cuando todos ellos habían sido públicos y revelados en los medios de comunicación. La Corte insistió en que "es la originalidad y no el tiempo, el esfuerzo, la dedicación y sudor de la frente que se gasta en la investigación" lo que permitía la protección de los derechos de autor Miller v. Universal City Studios, Inc., 650 F. 2d 1365 (5th Cir. 1981).

18 Tribunal Andino de Justicia, Proceso 121-IP-2013. "Lo que se protege es la individualidad, originalidad y estilo propio del autor para manifestar sus ideas". 
a la personalidad única de su autor, ${ }^{19}$ ya que, en sus palabras, "la originalidad exige que la obra presente una individualidad muy característica, que plasme la impronta de su autor de manera clara y evidente. La originalidad supone un aporte individual y creativo, es decir, producto de un pensamiento independiente". ${ }^{20}$

Por consiguiente, habría que dejar de ser tan sensibles y ofendernos cuando alguien reproduce una frase, oración, definición o idea genérica, pues allí no hay plagio:

Por ejemplo, si al interior de un párrafo un autor dice que 'Lima es la capital del Perú, no puede acusársele de plagio simplemente por el hecho de que otros autores, también al interior de determinados párrafos, han escrito previamente que 'Lima es la capital del Perú'. No hay nada de original en esta oración. Cualquier persona podría escribirlo a partir de su propio pensamiento. ${ }^{21}$

De cualquier forma, hay que decir que la originalidad se presume y quien la niegue debe probarlo, "de manera que la prueba de que la obra del actor no tiene ninguna originalidad incumbe a la parte demandada" (Kerever, 2003, p. 206). ${ }^{22}$

Tal vez, la mejor forma de entender la originalidad es estudiando la forma en la que se ha tratado en los diversos ámbitos de la creación artística.

\subsection{Originalidad en las novelas}

Muchos consideran que Gabriel García Márquez, al escribir Memoria de mis putas tristes reescribió la novela La casa de las bellas dur-

19 Tribunal Andino de Justicia, Proceso 295-IP-2019.

20 Tribunal Andino de Justicia, Proceso 295-IP-2019.

21 Ibídem.

22 En palabras del Tribunal Andino de Justicia : "El que alega un hecho tiene la carga de probarlo. En consecuencia, quien imputa a un tercero haber plagiado un texto suyo tiene la carga de probar esta circunstancia; es decir, tiene la carga de probar que su texto es original y que el texto del tercero es una copia del suyo. El tercero no tiene la carga de probar que el texto materia de debate no es original, pero nada impide que lo haga" (Proceso 295-IP-2019). 
mientes del japonés Yasunari Kawabata. ¿Será cierto que el Nobel colombiano "copió" su última novela? Al fin y al cabo, ambas obras tienen muchas similitudes: las dos son novelas y tienen cinco capítulos cada una; el personaje de Gabo es un viejo de 90 años y el de Kawabata tiene 67; la atmósfera del insoportable calor del trópico de la obra del colombiano contrasta con las estaciones del otońo y el invierno del japonés; $y$, en ambos casos, el personaje principal busca a una prostituta joven y virgen. Si observamos con detenimiento, ambas historias se parecen y son distintas al mismo tiempo.

Si aplicamos el principio del derecho de autor según el cual las ideas no tienen dueño y lo que es susceptible de ser protegido con este derecho es la originalidad de su forma de expresión, es decir, la selección y arreglo de las palabras en el caso de las novelas, podemos llegar a una primera conclusión: en la literatura, la originalidad no está en los temas ni en los argumentos, sino en cómo son narrados una y otra vez. Si esto es así, entonces Memoria de mis putas tristes, con su atmósfera tropical, tiene suficientes méritos para ser original.

Ahora bien, ¿será que la originalidad la da quien inspira la novela? Para empezar, hay que dejar claro que la persona que sirve de musa no es dueńa de nada. Es más, ni ella ni la que tiene una idea para una historia son titulares de ningún derecho por una razón muy sencilla: las ideas o el contenido conceptual de las obras literarias, artísticas y científicas no son objeto de protección por el derecho de autor. Este derecho protege exclusivamente la forma literaria, plástica o sonora, cómo las ideas son descritas, explicadas, ilustradas o incorporadas en obras literarias, artísticas y científicas. ${ }^{23}$

El caso de Luis Alejandro Velasco contra Gabriel García Márquez ilustra este punto. Velasco, un marinero que en una ocasión naufragó en el mar y permaneció más de una semana perdido en una balsa sin alimento, fue el protagonista de una de las novelas de García Márquez, titulada Relato de un náufrago. Una vez publicada, Velasco solicitó que se le reconociera que él era coautor de la obra, puesto que le había contado su historia al autor, quien primero escribió una crónica para el periódico El Espectador y, unos años después, la aclamada novela. ${ }^{24}$

23 Art. 6, L. 23/1982.

24 Tribunal Superior de Bogotá, Sala Civil, Sentencia del 27 de enero de 1994. 
Velasco también argumentaba que el mismo García Márquez (2020) había escrito en el preámbulo de su libro: "Los derechos de autor, en consecuencia serán para quien los merece: el compatriota anónimo que debió padecer diez días sin comer ni beber en una balsa [...]" (p. 11). Sin embargo, Velasco perdió el proceso ante las autoridades colombianas, pues estas, luego de analizar los hechos, determinaron que no había coautoría en la obra toda vez que el marinero simplemente le dio la idea al escritor y le contó verbalmente su historia, pero no participó en la selección de las palabras, en el orden de los capítulos ni, en general, en la redacción del relato.

\subsection{Originalidad en las fotografías}

Otro caso de estudio son las fotografías. ¿Qué tan original puede ser una fotografía? Algunos consideran que no son originales, puesto que son una copia de la realidad. Sin embargo, la jurisprudencia norteamericana dijo, hace más de un siglo, que hay derechos de autor sobre la forma personal, intelectual y original que escoge el fotográfo al capturar la imagen, la luz, la decoración y los ángulos. ${ }^{25}$ Específicamente, la jurisprudencia norteamericana ha señalado que una fotografía puede ser original porque ha plasmado la realidad de manera única, fue tomada en el momento perfecto o porque recrea una escena muy especial. ${ }^{26}$ Pero no hay que exagerar. En el país del norte también encontramos un fallo que dice que la sola selección del lente, la luz, la posición, el filtro e incluso la clase de rollo no necesariamente determinan que la foto sea original. ${ }^{27} \mathrm{Al}$ fin y al cabo, el derecho de autor no protege el esfuerzo, el tiempo o "el sudor de la frente" que una persona -en este caso, un fotógrafo- pone en su obra, sino la creatividad que se observa en el resultado. Un fotógrafo puede haber dedicado mucho interés y tiempo a realizar una obra, pero el resultado puede no ser original. Para ilustrar esta última afirmación, el juez citó el caso Bridgeman Art Library, Ltd. v.

Rad. 11985.

25 Burrow-Giles Lithogtaphic v. Sarony, 1884.

26 Mannion v. Coors Brewing Co., cit., supra.

27 Ídem. 
Corel Corp. Aquí se estableció que unas fotografías de unas obras de la pintura clásica carecían de derechos de autor porque el fotógrafo había creado unas obras idénticas a las pinturas originales. Si bien es cierto que para lograr ese resultado el fotógrafo requirió mucho esfuerzo y pericia y tuvo que escoger muy bien el ángulo, el rollo y la luz, el resultado no fue original debido a que en las fotografías no quedó nada de su personalidad. ${ }^{28}$

\subsection{Originalidad en las compilaciones de información}

Una compilación puede ser protegida mediante derechos de autor si y solo si la selección, arreglo y disposición de sus elementos tiene un mínimo de originalidad o, por lo menos, una chispa de creatividad personal. La jurisprudencia estadounidense ha aceptado que mientras algunas enciclopedias y libros de cocina son protegibles a través de los derechos de autor porque la información ha sido dispuesta de una manera personal y original, los directorios telefónicos en los que aparece la información organizada en orden alfabético no, aunque hayan requerido muchos trabajo: los derechos de autor no protegen el sudor de la frente (sweat of the brow), sino la originalidad. ${ }^{29}$

Tratándose de compilaciones de normas o jurisprudencia, al menos en Colombia no se puede hablar de derechos de autor sobre la información en sí misma, puesto que la Ley 23 de 1982, en su artículo 41, señala que les es permitido a todos reproducir la Constitución, leyes, decretos, ordenanzas, acuerdos, reglamentos, demás actos administrativos y decisiones judiciales bajo la obligación de conformarse puntualmente con la edición oficial.

Si esto es así y el texto de la Constitución, leyes, decretos, ordenanzas, acuerdos, reglamentos, demás actos administrativos y decisiones judiciales se pueden reproducir libremente, entonces en las compilaciones de legislación y jurisprudencia lo que está protegido mediante derechos de autor es solo la originalidad en el sistema de

28 Bridgeman Art Library, Ltd. v. Corel Corp., 36 F. Supp. 2d 191 (S.D.N.Y. 1999).

29 Feist Publications, Inc v. Rural telephone Service Co., 499 U.S 240, 245-246 (1991). 
selección o de organización de la información. En este sentido, consideramos que no existen derechos de autor sobre las compilaciones de legislación o jurisprudencia cuando la selección y organización de la información se hace utilizando uno o varios de los siguientes criterios: la fecha de la ley o la sentencia, los nombres de las partes, el juzgado o tribunal de procedencia, las normas o casos concordantes y los temas o descriptores. Ello, porque se trata de los criterios obvios que se utilizan para compilar este tipo de información y que excluyen de plano la calificación de tales obras como compilaciones personales, originales o con una chispa de creatividad.

Esto no significa que las editoriales deban desarrollar su objeto social sin ninguna protección, sino que pueden optar por proteger sus compilaciones legales mediante otras herramientas jurídicas, como son las marcas o los contratos. De hecho, las más grandes editoriales jurídicas americanas, como Lexis Nexis y Westlaw, tienen centenares de marcas en uso y registradas para identificar sus productos. Por ejemplo, el hecho de organizar y mostrarle al usuario la información jurídica con notas de vigencia está protegido por Reed Elsevier, nuevo dueño de Lexis Nexis, a través de las marcas Shepards, Shepards. com, Shepard's Alert y Sheparize. Otra opción puede ser proteger la propiedad sobre las compilaciones a través de contratos que amparen en forma supletoria lo que no ampara el derecho de autor. Es el típico caso de los "términos y condiciones" de los sitios de internet y de las licencias que suscribe el usuario de bases de datos, en las cuales este se obliga a no divulgar ni dar a conocer a terceros su contenido.

\subsection{Obras de arquitectura}

En las obras arquitectónicas se ha dicho que la "originalidad aparece en aquellas creaciones del arte de la construcción cuya forma difiere de las obras cotidianas o habituales" (Ruipérez de Azcárate, 2012, p. 168). Esto significa que la originalidad aparece cuando el autor le imprime su sello personal a la obra independientemente de las limitaciones que impone el presupuesto, de las reglamentaciones locales y zonales de construcción, de la tecnología y de los materiales disponibles en el área. ${ }^{30}$

30 "Architecture is not much more than a tree. Trees grow in line with its sur- 
Es difícil encontrar la originalidad en las obras arquitectónicas porque un gran porcentaje de los arquitectos se dedica a lo que los americanos llaman bread and butter arquiteture para referirse a la elaboración y construcción de casas sencillas y edificios comerciales estándar, los cuales no están protegidos por el derecho de autor pues carecen de originalidad.

Al referirse específicamente a obra arquitectónica, el Tribunal Andino de Justicia ha insistido en que la originalidad debe buscarse fuera de los elementos necesarios para darle funcionalidad al edificio y para cumplir con las normas técnicas y urbanísticas.

Piénsese en una figura de un edificio elaborado con especificaciones técnicas de construcción antisísmica que se basen en elementos externos; todos los edificios que se hagan con esas especificaciones comparten ciertas características comunes. También piénsese en esquemas funcionales de construcción: pasos obligados, espacios para que el aire fluya, techos en forma de $\mathrm{V}$ invertida, entre otros; todos las construcciones que se hagan tendrán dichos rasgos característicos de funcionalidad. Por lo tanto, al determinar la originalidad se debe tener en cuenta estos elementos necesarios. Si el arquitecto le imprime ciertos rasgos personales, diferenciadores, que reflejen su espíritu creativo, como sería el caso de una fachada que diferencie totalmente una obra de las otras del mismo género, estaríamos ante una obra arquitectónica. ${ }^{31}$

En resumen, si combinamos los mencionados criterios legales y jurisprudenciales aplicables, podemos decir que al analizar la originalidad de una obra arquitectónica, hay que trabajar caso por caso, ${ }^{32}$ separar los elementos esenciales para darle funcionalidad al edificio como son los "pasos obligados, espacios para que el aire fluya, techos

roundings. But some architects without consideration for the environment, creating a particular order. I do not, because I think we do the job only when it settled the environment”. Luis Sánchez Blasco (2015, párr. 2) le adjudica esta frase al arquitecto Toyo Ito.

31 Tribunal Andino de Justicia, Proceso 121-IP-2013.

32 Tribunal Andino de Justicia, Proceso 121-IP-2013. 
en forma de $\mathrm{V}$ invertida” ${ }^{33}$ y separar toda creación que se haga para dar cumplimiento de normas legales.

En arquitectura, la originalidad es una cualidad que no tiene que aparecer aislada, sino que puede encontrarse en la combinación de varios elementos. La originalidad "puede derivar tanto de sus concretos elementos individuales (por ejemplo, su fachada) como de la combinación de esos elementos, aun cuando individualmente considerados carezcan de originalidad (por ejemplo, de la forma de distribuir los espacios)". ${ }^{34}$

\subsection{La paradoja de la moda}

En teoría, a los diseños de prendas de vestir y a los accesorios se les puede aplicar cualquiera de las figuras de la propiedad intelectual -derecho de autor o propiedad industrial- si cumplen con los requisitos legales establecidos en la ley para cada una de ellas. Sin embargo, en la práctica, se complica acceder a estas figuras porque la moda es cambiante por naturaleza y una prenda de vestir que resulta valiosa para su diseñador y para sus competidores en una temporada específica puede perder su valor en la siguiente (precisamente porque "ha pasado de moda"). ${ }^{35}$

33 En España, al comparar dos proyectos, un Tribunal encontró que ambos compartían el esquema primario que es origen "del 95\% de las ideas proyectuales de los Arquitectos [...]”. SAP de Granada, número 510/1997, de 30 de junio de 1997.

34 Ibíd. También lo considera así la jurisprudencia argentina: "Aparece [...] de una dificultad absoluta el pensar siquiera que se pueda prescindir de los principios y leyes físicas en la realización de una obra cualquiera de arquitectura”, pero "existe originalidad en ella a partir de la combinación absolutamente personal que es reflejada en la obra en su conjunto. La originalidad está acentuada en la diferente combinación que de los conocidos presupuestos son realizados por el autor”. Argentina, provincia de Córdoba, Cámara 5ta. Civil y Comercial, Sentencia del 30 diciembre 1996 (Disponible en: http://www. cerlalc.org/derechoenlinea/dar/index.php? mode=archivo\&id=386).

35 Hay modas que no caducan y algunos objetos se convierten en piezas clásicas. En la casa francesa de moda Hermès hay una lista de espera de un año para obtener el clásico bolso Kelly, que se hizo famoso en 1956 cuando la princesa Grace de Mónaco apareció con él en la portada de la revista LIFE. El 
Es más, para algunos, la moda desafía la idea según la cual cuando existen "más derechos" se asegura "más creatividad", pues en esta industria parece ser que la ausencia de derechos alimenta el proceso creativo, toda vez que los diseñadores de moda son libres de pedir prestado, imitar, revivir, recombinar, transformar y compartir todo tipo de elementos de diseño sin tener que pagar regalías o preocuparse por infringir derechos de propiedad intelectual (Cox y Jenkins, 2005).

\section{6. ¿Son originales las creaciones procedentes de la inteligencia artificial?}

La inteligencia artificial supone varios retos para los derechos de autor. El primero es el referido a la propiedad de los inputs, es decir, los datos con los que se alimenta la máquina con la finalidad de desarrollar algoritmos que ofrezcan creaciones de inteligencia artificial. Tales datos con frecuencia están protegidos por derechos de autor, con lo cual surge la necesidad de determinar en qué medida es necesaria la autorización del titular para utilizar esos contenidos y si sería conveniente establecer alguna excepción para que esa autorización no sea necesaria. El segundo tiene que ver con los outputs, es decir, los resultados que se derivan de la introducción de datos en ese modelo de inteligencia artificial, resultados que pueden ser una simple decisión, más datos o bien una creación artística nueva, cosa que ocurrirá sobre todo si el sistema se alimenta con creaciones intelectuales anteriores. El caso típico es el del proyecto The Next Rembrandt, ${ }^{36}$ en el cual Microsoft combinó datos y algoritmos para remplazar el pincel del famoso pintor y crear nuevas obras: arte artificial.

¿En qué medida se podría decir que el resultado del algoritmo es una creación original? ¿Quién debería ser considerado titular de los derechos sobre esa obra: las personas que hay detrás de la máquina, la máquina como tal, el modelo de inteligencia artificial? ¿Debería pensarse que se trata de una obra en el dominio público?

clásico traje de Chanel -diseñado por Coco Chanel en la década de 1930- se sigue vendiendo actualmente a 5000 dólares estadounidenses.

36 Disponible en: https://www.nextrembrandt.com/. 


\section{Plagio}

No existe una definición legal de esta figura, pero el Glosario de la Organización Mundial de la Propiedad Intelectual (Organización Mundial de la Propiedad Intelectual, 1980, voz 188) ofrece las siguientes directrices:

- "Plagio es el acto de ofrecer o presentar como propia la totalidad o parte de la obra de otra persona, en una forma o contexto más o menos alterados".

- "No ha de confundirse el plagio con la libre utilización de las meras ideas o métodos de creación tomados de otra obra al crear una obra original".

De cualquier forma, para que se produzca el plagio deben concurrir los siguientes factores: ${ }^{37}$

1) La utilización no autorizada de la obra ajena, en todo o en parte, reproduciéndola de manera literal (caso en el cual se denomina "plagio servil") o simulada (en cuyo caso la doctrina le denomina "plagio inteligente"), es decir, introduciéndole a la obra algunas modificaciones que buscan disimular la copia realizada. En este sentido, el plagio constituye una copia o reproducción no autorizada de la obra, sin detrimento de que también se puedan vulnerar otros derechos patrimoniales e, inclusive, el derecho moral de integridad.

2) La suplantación del autor, al presentar la obra a nombre de persona distinta del autor verdadero, lo que constituye una vulneración del derecho moral de paternidad. ${ }^{38}$

En resumen, existen tres tipos de plagio: el servil, que es la copia literal, el inteligente, que es la copia simulada, y la suplantación del autor. Así lo expuso la Dirección Nacional de Derecho de Autor de Colombia al resolver una consulta de un ciudadano. ${ }^{39}$ Como el plagio servil y la suplantación de autor son bastante evidentes, nos

37 Dirección Nacional de Derecho de Autor de Colombia, Concepto: 1-201331778, Plagio.doc

38 Ibíd.

39 Ibíd. 
vamos a referir al plagio inteligente, es decir, a aquella copia simulada que requiere demostrar la coincidencia o similitud de una parte suficientemente significativa de una obra con los elementos originales de una creación intelectual. Esta comparación debe hacerse teniendo en cuenta el tipo de obra de que se trate y atendiendo más a las semejanzas que a las diferencias. ${ }^{40}$

Precisamente, lo más difícil para establecer el plagio inteligente es determinar qué tan significativas o no son las similitudes y entre los elementos originales de una y otra obra. La jurisprudencia norteamericana, la espańola y la de la Comunidad Andina han ideado varios criterios para responder esta cuestión. Uno de ellos es el Test Hand, nombrado así en honor al juez norteamericano Learned Hand: ${ }^{41}$

- Para determinar si una obra es idéntica a otra lo primero que hay que hacer es verificar si hay identidad "literal".

- Si no hay identidad "literal", hay que proceder a determinar si hay similitud sustancial, o substantial similarity, entre las obras que se comparan. Para el efecto, hay que seguir los siguientes pasos:

»Sustraer todos los elementos no protegibles por el derecho de autor, como serían las scènes à faire americanas, las banalités francesas o los lugares comunes en castellano.

"Buscar si hay similitud sustancial en lo que queda de la obra aplicando el Test Resumen, o Abstraction Test, que se explica de la siguiente forma: no hay plagio entre dos obras cuando, a pesar de que se puede resumir su argumento de la misma forma, entre una y otra hay detalles, personajes, escenas y sucesos que les dan personalidad propia.

Siguiendo la doctrina del juez Learned Hand, se puede decir que entre más detallado sea el formato, mayor protección otorgará el derecho de autor. Así fue como en Brasil se protegió el formato del célebre reality Big Brother. En Endemol v. TV SBT, la productora holandesa había entrado en negociaciones con la cadena brasilera para transmitir el programa en televisión en ese país. TV SBT y Endemol no llegaron a un acuerdo y la primera tomó la decisión de transmitir

40 Ibíd.

41 Nichols v. Universal Pictures Corp., 45 F.2d 119 (2d Cir. 1930). 
su propia versión del reality: Casa Dos Artistas. Endemol, por supuesto, demandó. TV STB alegó en su defensa que la idea de encerrar a un grupo de personas en una casa para observar su conducta no era una idea novedosa, pues, en su sentir, a manera de ilustración, "la obra 1984 de George Orwell trata[ba] con este tema [...]". La Corte, sin embargo, estimó lo siguiente con respecto a Big Brother: ${ }^{42}$

[Big Brother] no se limita a espiar [a] personas encerradas en una casa durante un cierto período de tiempo; [...] contempla un programa con principio, mitad y fin, y con una descripción minuciosa, no sólo de la atmósfera en la que las personas vivirán durante un cierto período de tiempo, sino también de los lugares donde estarán las cámaras. El formato se compone de detalles tales como el uso de micrófonos atados a los cuerpos de los participantes durante las 24 horas del día, los estilos de la música, la forma a través de la cual los participantes tendrán contacto con el mundo exterior, las actividades, entre otros. Las situaciones de imagen y audio capturadas para cientos de miles de personas a través de las inserciones diarias en la programación de los servicios de televisión y a través de Internet con la consiguiente explotación comercial es también una característica única del formato.

TV STB fue condenada a pagar perjuicios a Endemol por su infracción al derecho de autor sobre el formato de Big Brother. ${ }^{43}$

El Test Resumen se puede explicar gráficamente de la siguiente forma: se dibuja una línea recta en cuyo extremo izquierdo se encuentra un resumen sencillo de la obra y, en el extremo derecho, su puesta en escena. Mientras más a la derecha, es decir, mientras más parecidos sean los detalles, más posibilidades habrá de que se configure plagio por similitud sustancial (Tobón Franco y Varela Pezzano, 2010).

Tratándose de obras arquitectónicas, por ejemplo, no solo habría que extraer los lugares comunes, sino también los elementos

42 Extracto en: www.swanturton.com/ebulletins/archive/JKCBigBrotherFormat. aspx. La traducción es de los autores.

43 Corte Suprema de La Haya, Castaway Television Productions Ltd. \& Planet 24 Productions Ltd. v. Endemol, Sentencia del 16 de abril de 2004. 
esenciales para darle funcionalidad al edificio y toda creación que se haga para dar cumplimiento a normas técnicas y de urbanismo. ${ }^{44}$ $\mathrm{Al}$ comparar obras de arte se han expuesto varios criterios. Uno de los casos emblemáticos es el de Steinberg $v$. Columbia Pictures en Estados Unidos ${ }^{45}$. Steinberg, un famoso ilustrador, creó el póster clásico de Nueva York que utiliza la revista The New Yorker. Posteriormente, Columbia Pictures utilizó un póster "similar" al de Steinberg para promocionar la película Moscow on the Hudson, sobre las aventuras de un inmigrante ruso en Nueva York personificado por el actor Robin Williams. Steinberg demandó a Columbia Pictures y la Corte hizo el siguiente análisis:

* Nadie es dueńo de la idea de usar un mapa para ilustrar algo.

* Está claro que un mapa de la ciudad de Nueva York debe incluir edificios, calles y vehículos (lugares comunes), pero el demandante no alega la copia de lugares comunes que tiene cualquier mapa de una ciudad, sino del estilo mediante el cual él, como ilustrador, expresó esos elementos.

* El estilo de cada artista es algo individual que se observa en la forma como expresa sus ideas. El estilo imaginativo y exagerado del mapa de la ciudad de Nueva York de Steinberg es original hasta el punto en que se considera la firma del artista o su hallmark.

* A primera vista se observa que el estilo utilizado en las dos ilustraciones es similar.

* La puesta en escena de las dos ilustraciones es similar, pues ambas escogieron una avenida con varias intersecciones.

* Ni siquiera la exhibición de la ciudad de Moscú al fondo ni el uso de algunos sitios emblemáticos de la ciudad de Nueva York, como el Empire State Building, son susceptibles de eliminar la similitud sustancial entre las dos ilustraciones. Al fin y al cabo, dice la sentencia, "como escribió el juez Learned Hand, ningún plagiario puede excusar sus malas acciones mostrando la proporción de la obra que no copió”. ${ }^{46}$

44 Tribunal Andino de Justicia, Proceso 121-IP-2013.

45 Steinberg v. Columbia Pictures Industries, 663 F. Supp. 706 (S.D.N.Y. 1987) (como se citó en Tobón Franco y Varela Pezzano, 2010, p. 192).

46 "No plagiarist can excuse the wrong by showing how much of his work he 


\section{NEW YOORKER}
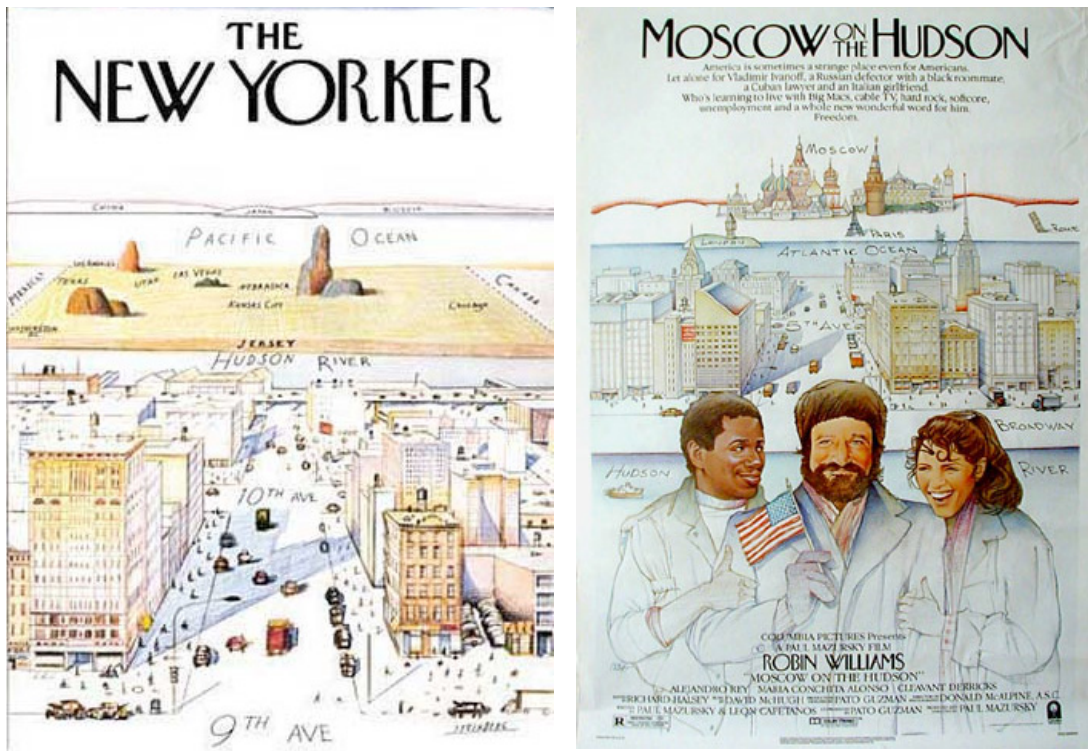

Figuras sobre plagio en obras de arte (fuente: publicada en Steinberg v. Columbia Pictures Industries).

En los años recientes se ha aplicado otro test para determinar la identidad sustancial entre dos obras, sobre todo si son obras de arte, por cuanto ellas, a diferencia de las obras literarias, se pueden apreciar como un todo con una sola mirada. Se trata del test del concepto general y del sentimiento que expresan (concept and feel, tone and mood).

En la música es común encontrar casos de plagio entre los artistas. Algunas veces, los músicos copian inconscientemente; y otras, adrede. En el primer caso, los jueces hablan de copia inconsciente cuando encuentran probado que el autor del plagio tuvo acceso a la obra original, pero no es claro que su intención fuera plagiarla, como sucedió en Bright Tunes Music Corp. v. Harrisongs Music, Ltd., ocurrido en Estados Unidos en 1976. El juez estadounidense falló que George Harrison (exintegrante de Los Beatles) seguramente conocía la melo-

did no pirate" (Sheldon v. Metro Goldwyn Pictures Corp., 81 F. (2d. Cir), disponible en: https://riu.austral.edu.ar/bitstream/handle/123456789/1499/ Dos\%20problemas\%20jur\%C3\%ADdicos\%20alrededor\%20de\%20 las $\% 20$ fotograf $\%$ C3\%ADas.pdf?sequence $=1$ ). 
día de $H e$ is so fine porque había sido un gran éxito (top-hit status en 1963) cuando grabó su obra My sweet lord (1970) y la había copiado o adaptado sin intención porque las notas musicales combinaban a la perfección con las palabras, que eran el motivo de su inspiración para componer en ese momento: Hallelujah y Hare Krishna.

¿Copió Harrison intencionalmente la melodía de 'He is so fine'? No, no creo que lo haya hecho deliberadamente. Sin embargo, es claro que 'My Sweet Lord' (la obra de Harrison de 1970) es sustancialmente similar a 'He is so fine' (compuesta por Ronald Mack y convertida en un éxito por el grupo denominado 'The Chiffons' en 1963), solo que con diferente letra. Esto, bajo la ley es una infracción a los derechos de autor y no lo es menos porque el plagio haya sido cometido de manera inconsciente. (Como se citó en Tobón Franco y Varela Pezzano, 2010, p. $229^{47}$

¿Cuántas notas musicales de una obra deben aparecer en otra para poder afirmar que hay plagio? ¿Puede esto determinarse de manera numérica o, incluso, por porcentajes? No parece probable. Algunos autores señalan que una obra musical solamente puede plagiar a otra cuando la audiencia (quien escucha) confunde ambas melodías dadas las similitudes del sonido (Sherman, 1977, p. 145). No obstante, esta regla debe tener excepciones, pues hay casos en los que, aun cuando el público no se confunde, sí puede existir plagio. Ocurre, por ejemplo, cuando una canción de rap copia una canción pop. ${ }^{48}$

\section{Las obras derivadas}

Puede suceder que la obra se copie para transformarla. Una obra derivada es la que resulta de la transformación de otra preexistente. Los

47 Bright Tunes Music Corp. v. Harrisongs Music, Ltd., 420 F. Supp. 177 (S.D.N.Y. 1976). La Corte de Apelaciones confirmó este fallo en su totalidad en 1983, pero los procesos judiciales por el monto de los dańos y perjuicios solo terminaron en 1991, en un acuerdo por 5.4 millones de dólares.

48 Así lo falló una Corte del Distrito de Nueva York en el caso Grand Upright Music, Ltd. v. Warner Brothers Records, Inc., 780 F. Supp. 182 (S.D.N.Y. 1991). 
ejemplos clásicos de este tipo de creaciones son las traducciones, las adaptaciones, las parodias y las compilaciones. ${ }^{49}$

Una obra derivada no es una copia, sino una variación -en mayor o menor medida- de una obra anterior. ${ }^{50}$ El problema consiste en determinar qué tan original es esa variación para poder predicar un derecho de autor sobre esta. Algunas obras derivadas, a pesar de tomar como base otras anteriores, presentan un grado de creatividad que les permite ser consideradas "originales" y obtener la protección ofrecida por el derecho de autor, claro está, sin perjuicio de los derechos del titular sobre la obra preexistente.

En general, la mayoría de las legislaciones prevé que quien pretenda realizar una obra derivada debe pedirle autorización al titular de la obra original, a menos que esta se encuentre en el dominio público. ${ }^{51}$ Cuando la autorización para realizar la obra derivada es negada, el autor de esta, aunque haya ańadido elementos originales, no adquiere ningún derecho. Esto le ocurrió a un niño de 16 años en Aix-en-Provence (Francia), que, inocentemente, decidió traducir el libro Harry Potter and the Deathly Hollows del idioma inglés al francés sin la autorización de los editores del libro. El joven adolescente tuvo que pasar una noche en la cárcel y ofrecer una disculpa a J. K. Rowling, autora del libro, por la obra derivada no autorizada que había publicado y compartido en internet. ${ }^{52}$

Ahora bien, si la obra traducida está en el dominio público, el traductor es autor de su propia versión, pero no podrá oponerse a que otros hagan traducciones distintas de la misma obra y obtengan, si su obra así lo amerita, la protección del derecho de autor. ${ }^{53}$

Atención especial amerita el tema del derecho moral a la integridad de la obra que tiene el autor original. Los franceses han sostenido que en la obra derivada tal derecho se viola de dos formas:

49 La profesora Delia Lipszyc (1993, p. 111) también menciona las actualizaciones, las antologías, los resúmenes y los extractos.

50 Véase Goldstein (1983).

51 Véase, además, una opinión sobre este tema en Landes y Posner (2003, p. 109).

52 Véase la noticia en Doctorow (2007).

53 Art. 14, Ley 23/1982 de Colombia. 
o Cuando el "espíritu" de la obra original se distorsiona. ${ }^{54}$ Esta particular situación es extremadamente subjetiva, pues siempre existirá la dificultad de definir qué es "espíritu” y qué no lo es.

o Cuando la "dignidad" del autor se distorsiona. ${ }^{55}$

Para solucionar estas dificultades se recomienda que el autor original y el autor derivado suscriban un acuerdo por escrito en el que determinen claramente la intención y alcance de la autorización y el espíritu de la obra original. Una vez autorizada la adaptación, el autor deberá "sufrir" todos los cambios que el autor de la obra derivada realice y que posiblemente puedan afectar su derecho moral. ${ }^{56}$

Finalmente, el autor derivado tiene la obligación de abstenerse de utilizar su nombre como si fuera el autor de la obra preexistente (Dittrich y Kucsko, 1981, p. 21), ya que esto daría una impresión equivocada acerca de la naturaleza originaria de su creación.

\section{Competencia desleal y enriquecimiento sin causa}

La competencia desleal y el enriquecimiento sin causa serían los dos últimos escollos a sortear para que una copia sea lícita.

El término "competencia desleal" está compuesto por dos nociones: "competencia" y "deslealtad". Por consiguiente, debe quedar claro que las normas sobre competencia desleal no castigan la competencia per se, sino las prácticas competitivas desleales.

La Ley 256 de 1996, que es la ley que sanciona la competencia desleal en Colombia, califica los siguientes actos como prácticas competitivas desleales: ${ }^{57}$

- Actos o hechos que resulten contrarios a las sanas costumbres mercantiles.

54 Molinard v. Société Les Fromagers Savoyards, Tribunal de Grande Instance de Annecy, Sentencia del 10 de septiembre de 1998.

55 Tribunal de Grande Instance de París, Sentencia del 7 de enero de 1969.

56 Sobre este tema, véase una explicación aún más detallada en Strowel (1993, pp. 356-357).

57 Están previstos en el artículo $7^{\circ}$ de la Ley 256 de 1996 y en el Convenio de París, aprobado en Colombia mediante la Ley 178 de 1994, artículo 10 bis, numeral $2^{\circ}$. 
- Actos o hechos que resulten contrarios al principio de la buena fe comercial.

- Actos o hechos contrarios a los usos honestos en materia industrial o comercial.

- Actos o hechos encaminados a afectar la libre decisión del consumidor.

- Actos o hechos que afecten el funcionamiento concurrencial del mercado.

Podría pensarse que para detectar si hay competencia desleal habría que cambiar en todos los casos la expresión "actos y hechos" por "copia" y así determinar si ha habido o no competencia desleal con tal comportamiento. En todo caso, hay que tener claro que lo censurable no es que un comerciante intente quitarle a otro la clientela, pues ese es un fin legítimo en el mercado. Lo que se reprocha es que lo haga utilizando medios indebidos, tales como actos de desorganización, de confusión, de engaño, de descrédito, de imitación, explotación de reputación ajena, violación de secretos, inducción a la ruptura contractual y violación de normas y pactos de exclusividad, entre otros. Así lo explicó la Superintendencia de Industria y Comercio al fallar un caso de competencia desleal. ${ }^{58}$

Quien desee iniciar un proceso por competencia desleal debe verificar la presencia de las siguientes situaciones: en el comercio, vale decir, con un determinado standard de usos sociales y buenas prácticas mercantiles. ${ }^{59}$ La doctrina ha dispuesto que se compite lealmente cuando existe "claridad y diferenciación de las ofertas; actuación de los oferentes en el mercado basada en su propio esfuerzo; respeto de la legalidad; prohibición de la arbitrariedad, y libertad de decisión de los consumidores". ${ }^{60}$

58 Colombia, Superintendencia de Industria y Comercio, Resolución 11090, abril 29/03. 
2. Que la conducta haya sido realizada en el mercado.
La conducta desleal debe haber sido realizada en el mercado con fines concurrenciales. La jurisprudencia ha definido el mercado como el escenario en el que tanto oferentes como consumidores buscan satisfacer necesidades propias y ajenas. El artículo $2^{\circ}$ de la Ley 256 de 1996 dispone que la finalidad concurrencial de un acto se presume cuando este, por las circunstancias en que se realiza, sirve para mantener o incrementar la participación en el mercado de quien lo realiza o de un tercero.

3. Que la conducta haya sido realizada por cualquier persona, independientemente de su calidad de comerciante.

En Colombia, las normas sobre competencia desleal se aplican a todos los participantes en el mercado, sean o no comerciantes, sean o no competidores. ${ }^{61}$ Según la doctrina, en el mercado participa todo aquel cuya actividad tiene que ver con el intercambio comercial de productos o servicios. ${ }^{62}$

La expresión "que tenga una finalidad concurrencial" quiere decir que la conducta haya sido realizada con el fin de mantener o incrementar la participación en el mercado del actor o de un tercero. ${ }^{63}$ Al respecto, la Ley 256 de 1996 explica que tal finalidad se presume cuando el acto resulta idóneo para mantener o incrementar la participación en el mercado de quien lo realiza o de un tercero.

5. Que la conducta produzca o esté llamada a producir efectos en el mercado colombiano, ${ }^{64}$ independientemente del lugar donde haya sido desarrollada (Velandia, 2001).

De esta manera, quien considere que su obra fue copiada puede demandar al copista en una acción por competencia desleal si el plagio se hizo con fines comerciales, violando las buenas prácticas mercantiles o con el ánimo de mantener o incrementar la participación en el mercado. Esta conducta tiene efectos en Colombia.

59 Colombia, Superintendencia de Industria y Comercio. Sentencia 005, abril 3/06.

60 Bercovitz (1992).

61 De hecho, la Ley 256 de 1996 establece en el artículo $3^{\circ}$ que su aplicación no podrá supeditarse a la existencia de una relación de competencia entre el sujeto activo y pasivo en el acto de competencia desleal.

62 Colombia, Superintendencia de Industria y Comercio. Resolución 11090, abril 29/03.

63 Ibíd.

64 Colombia, Ley 256 de 1996, artículo $4^{\circ}$ : “Esta ley se aplicará a los actos de competencia desleal cuyos efectos principales tengan lugar o estén llamados a tenerlos en el mercado colombiano". 
Otra de las opciones que tiene aquel que siente que otro se ha aprovechado de su trabajo es acudir a la justicia solicitando la aplicación del principio del enriquecimiento sin causa. Para ello, debe probar que concurren los siguientes elementos: ${ }^{65}$

- Un enriquecimiento positivo -aumento de un patrimonio- o negativo -se evita el menoscabo- del patrimonio de una persona.

- Un empobrecimiento correlativo de otra persona.

- Que el enriquecimiento se haya producido sin causa, es decir, sin fundamento jurídico.

En Colombia, el enriquecimiento sin causa está contemplado en el artículo 831 del Código de Comercio en los siguientes términos: "Nadie podrá enriquecerse sin justa causa a expensas de otro". En principio se podría pensar que su inclusión en el Código de Comercio hace que solo sea aplicable a comerciantes, es decir, a personas que profesionalmente se ocupan en alguna de las actividades que la ley califica como "mercantiles", pero existe jurisprudencia consolidada que permite suponer que también se aplica a relaciones civiles, eso sí, siempre que se cumplan los requisitos antes mencionados. ${ }^{66}$

Las demandas por enriquecimiento sin causa se tramitan mediante un proceso civil ordinario, un trámite que, al menos en Colombia, puede resultar muy demorado. Esta puede ser una de las razones por las cuales en la vida real se acude muy poco a esta figura.

La acción de tutela generalmente no es procedente, ni siquiera cuando la parte demandada ha aceptado su responsabilidad mediante una confesión, porque la mayoría de las veces "el derecho a la propiedad afectado por la no devolución del dinero no exhibe naturaleza fundamental" ${ }^{67}$

Adicionalmente, es importante precisar que para que proceda el enriquecimiento sin causa en Colombia es menester, como su nombre lo dice, que no haya causa, es decir, que la circunstancia que produjo el desplazamiento de un patrimonio a otro no haya sido ge-

65 Colombia, Corte Constitucional, Sentencia T-219/95

66 Colombia, Corte Suprema de Justicia, Cas. Civil, diciembre 19/12. Ref.: 54001-3103-006-1999-00280-01.

67 Colombia, Corte Constitucional, Sentencia T-219/95. 
nerada por un contrato o un cuasicontrato, un delito, un cuasidelito o una disposición expresa de la ley. ${ }^{68}$

De hecho, cuando el empobrecimiento se produce por la propia voluntad de la víctima, hay enriquecimiento o, mejor, empobrecimiento con causa. En efecto, en Colombia la jurisprudencia administrativa ha señalado que existe un elemento adicional para que se configure el enriquecimiento sin causa, que consiste en que

la causa del empobrecimiento, no haya sido provocada por el mismo empobrecido, toda vez que en dicho evento no se estaría ante un "enriquecimiento sin justa causa", sino ante la tentativa del afectado de sacar provecho de su propia culpa. ${ }^{69}$

La acción para reclamar por el enriquecimiento sin causa es la acción in rem verso, que es subsidiaria. Esto quiere decir que solo se puede acudir a ella cuando no existen otras opciones. En este sentido, la Corte Suprema de Justicia recientemente, señaló que

[l]a más notable de las características de la acción de enriquecimiento incausado, cual es la de la subsidiariedad. Todo el mundo conoce que dicha acción se abre paso solo en la medida en que no haya otro remedio que venga en pos del empobrecido. En otros términos, la vida de esta acción depende por entero de la ausencia de toda otra alternativa. ${ }^{70}$

\section{Conclusión}

Es posible, lícito e incluso recomendable copiar, crear sobre lo construido, siempre que al hacerlo se respete el derecho de autor, se abstenga de incurrir en actos de competencia desleal y se evite que se produzca un enriquecimiento sin causa.

68 Colombia, Corte Suprema de Justicia, Sentencia SC10113-2014, julio 31/14 citando a Colombia, Corte Suprema de Justicia, Sentencia 040/40.

69 Colombia, Consejo de Estado, Sentencia, marzo 30/06 (radicado 25000-2326-000-1999-01968-01(25662).

70 Colombia, Corte Suprema de Justicia, Sentencia julio 31/14 (radicado SC10113-2014) citando Colombia, Corte Suprema de Justicia, Sentencia, enero 11/2000.Ref.: Expediente 5208. 
La originalidad es el sine qua non del derecho de autor, por lo que una obra que no es original no está protegida por la PI.

El que una obra se encuentre en el dominio público hace que se pueda reproducir sin pagar contraprestación, pero es necesario citar el nombre de su autor, es decir, respetar el derecho moral de paternidad.

En ocasiones, los problemas de la copia no son solo consecuencia de la violación del derecho de autor, sino de otras normas, como las relacionadas con competencia desleal, el enriquecimiento sin causa o la violación de previsiones contractuales.

Las creaciones innovadoras es lo ideal, pero es bastante difícil que se presenten. Como dice la Biblia: "There is nothing new under the sun", ${ }^{71}$ por eso hay quien dice que la innovación está sobrevalorada. Steve Jobs decía: "La creatividad es el acto de conectar cosas".

\section{Bibliografía}

Bappert W. (1962). Wege zum Urheberrecht. Die geschichtliche Entwicklung des Urheberrechts Gedankens. Verkäufer kontaktieren.

Bercovitz, R. (1992). Competencia desleal, Código de Comercio, evaluación y perspectivas. Cámara de Comercio de Bogotá.

Bercovitz Rodríguez-Cano, R. (2015). Los derechos de propiedad intelectual sobre las obras arquitectónicas. Numeral 11. https://es.scribd.com/document/78246711/Dictamen-Sobre-Los-Derechos-de-Propiedad-Intelectual-Sobre-Las.

Brain, R. (1980). Art and society in Africa. Longman.

Cox, C. y Jenkins, J. (29 de enero de 2005). Between the Seams, A Fertile Commons: An Overview of the Relationship Between Fashion and Intellectual Property. A Norman Leare Center Conference. Annenberg Auditorium, USC Annenberg School for Communication. https://learcenter.org/pdf/RTSJenkinsCox.pdf.

Dittrich, R. y Kucsko, G. (1981). Urheberrecht. Manz.

Doctorow, C. (10 de agosto de 2007). French kid who translated Potter 7 faces charges. Boingboing. http://www.boingboing.net/2007/08/10/french-kidwho-trans.html.

Fabiani, M. (1987). Diritto di autore gastronomico. Diritto di Autore, (58). García Márquez, G. (2020). Relato de un náufrago. Editorial Debolsillo.

71 Biblia: Ecclesiastes 1:9. 
Goldstein, P. (1983). Derivative rights and derivative works in copyright. Journal of the Copyright Society, 30, 209-229.

Kahaner, L. (2003). Values, prosperity, and the Talmud. Business lessons from the ancient Rabbis. John Wiley and Sons.

Kerever, A. (2003). Crónica de jurisprudencia. Revue Internationale du Droit D'Auteur, (197).

Landes, E. M. y Posner, R. (2003). The economic structure of intellectual property law, Harvard University Press.

Lipzsyc, D. (1993). Derecho de autor y derechos conexos. UNESCO.

Molina, D. (11 de diciembre de 2016). El arte de la copia. La Nación. https:// www.lanacion.com.ar/cultura/el-criticoel-arte-de-la-copia-daniel-molina-para-la-nacion-nid1965906.

Organización Mundial de la Propiedad Intelectual. (1980). Glosario de la Organización Mundial de la Propiedad Intelectual. https://www.wipo.int/edocs/pubdocs/es/wipo_pub_816.pdf.

Pachón Muńoz, M. (1988). Manual de derecho de autor. Temis. p. 75

Ruipérez de Azcárate, C. (2012). Las obras del espiritu y su originalidad. Editorial Reus.

Sánchez Blasco, L. (31 de mayo de 2015). La arquitectura no es mucho más que un árbol - Toyo Ito. Cosas de arquitectos. Revista digital de arquitectura online desde 2009. https://www.cosasdearquitectos.com/2015/05/la-arquitecturano-es-mucho-mas-que-un-arbol-toyo-ito/.

Savitsky, T. (2004). Eastman Chemical Company. October 1990. Tomado de los materiales de clase del profesor Karl Jorda para el curso de "Intellectual Property Management” en Franklin Pierce Law Center.

Sherman, J. (1977). Musical copyright infringement: The requirement of substantial similarity. ASCAP Common Law Symposium, (92).

Strowel, A. (1993). Droit d'auteur et copyright, convergences ou divergences. Bruylant.

Tobón Franco, N. y Varela Pezzano, E. (2010). Derecho de autor para creativos. Editorial Gustavo Ibáñez.

Velandia, M. (2001). Competencia desleal por uso de signos distintivos. La propiedad inmaterial, (2), 101-116

Woodmansee, M. (1984). The genius and the copyright: Economic and legal conditions of the emergence of the 'author'. Eighteenth Century Studies, 17(4), 425-448.

\section{Jurisprudencia}

Corte Constitucional de Colombia, Sentencia T-381, septiembre 14/93.

Corte Constitucional de Colombia, Sentencia C-334, agosto 12/93.

Corte Constitucional de Colombia, Sentencia C-595, agosto 18/99.

Corte Suprema de Justicia de Colombia, Sentencia, agosto 11/88.

Dirección Nacional de Derecho de Autor de Colombia, Concepto 2-2005-329 del 14 de enero de 2005. 


\section{Natalia Celena Tobón}

Apuntes sobre la licitud de la copia

Dirección Nacional de Derecho de Autor de Colombia, Concepto: 1-201331778, Plagio.doc

Suprema Corte de los Estados Unidos, Atari Games Corp. v. Oman, 888 F.2d 878 (D.C. Cir. 1989).

Suprema Corte de los Estados Unidos, Burrow-Giles Lithogtaphic v. Sarony, 1884. Suprema Corte de los Estados Unidos, Sheldon v. Metro Goldwyn Pictures Corp., 81 F. (2d. Cir),

Suprema Corte de los Estados Unidos, White v. Samsung Electronics América, Inc. U.S. 951, 113 S. Ct. 2443, 124 L. Ed. 2 Ed. 660 (1993). Salvamento de voto del juez Alex Kozinski.

Tribunal Andino de Justicia, Proceso 121-IP-2013.

Tribunal Superior de Bogotá, Sala Civil, Sentencia del 27 de enero de 1994. Rad. 11985. 